\title{
Model Pendugaan Biomassa Diatas Permukaan Tanah Jenis Eucalyptus urophylla Pada Hutan Tanaman
}

\author{
Marulam MT Simarmata ${ }^{1}$ \\ Jan Ricky Tambunan ${ }^{2}$ \\ ${ }^{1}$ Dosen Fakultas Pertanian USI ${ }^{2}$ Alumni Fakultas Pertanian USI \\ E-mail : simarmatamarulam@yahoo.com
}

\begin{abstract}
Although global climate changes issue after which talked a few times ago but world concern seriously after Earth High Confrence in Rio de Janeirio Brazil on 1992. Ones alternatives in controlling the carbon concentration is through development of sink program, in which organic carbon resulted from fotosyntesis is fixed in biomass of forest vegetation or woody trees. Indonesia is very potential to develop carbon sink program because have third largest areas of tropical rain forest after Brazil and Zaire.

The most indicator to estimating forest potency for sink carbon is biomass. Biomass study is very important to studied forest ecosystem characteristic, expecially to analysis management system of sustainable principles. This research aim explain to ; 1) Now about above ground biomass component of eucalyptus urophylla (trunk, branch and twigs) from industrial forest plantations of PT. Toba Pulp Lestari; 2) to pile up allometric similarity for estimate above ground biomass from industrial forest plantations of TP. Toba Pulp Lestari.

Data of this research is collected with inventory of 21 trees sample from 7 age class. The trees sample is taken with purposive sampling and cut down. The biomass estimating which used in this research is non destructive models with pile up allometric similarity, to find fault correlation trees dimency with biomass. Choosing the best allometric similarity based on criterias determination correlation $\left(R^{2}\right)$, Mean Square Error (MSE) and Predicted Residual Sum of Square (PRESS) by Drapper et al, (1996).

The result from this research that; 1) Above ground biomass can be enhanced more by riding age class; 2) Trunck has been the largest biomass proporcy without the biomass proporcy of branch and twigs; 3) The moisture contents can be enhanced by riding age class and 4) Dimencion of trees ( $d b h$ and $h$ ) is the best parameters for estimate about above ground biomass.
\end{abstract}

Key words : Eucalyptus urophylla, biomass, carbon, estimating, forest plantations.

PENDAHULUAN

Perubahan fungsi lahan seperti konversi hutan merupakan salah satu penyebab penting perubahan iklim global, disamping peningkatan polusi udara di Indonesia, perubahan iklim global telah mempengaruhi ekosistem teresterial yaitu terjadinya perubahan suhu, ketersediaan air dan meningkatnya akumulasi karbon di atmosfir.

Indikator penting untuk menghitung potensi hutan sebagai sequester karbon adalah biomassa karena sebagian besar karbon 
yang diserap vegetasi hutan digunakan untuk membangun biomassa berkayu. Studi biomassa sangat penting dalam mempelajari produktifitas, siklus hara dan aliran energi. Selain itu data biomassa hutan sangat penting untuk mengetahui karakteristik ekosistem hutan terutama untuk analisa sistem manajemen yang tepat berdasarkan prinsip kelestarian.

Pendugaan biomassa dapat dilakukan dengan dua metode yakni metode pemanenan dan metode pendugaan tidak langsung. Pendugaan biomassa metode tidak langsung dilakukan dengan menyusun pendugaan biomassa model persamaan allometrik yang didasarkan pada hubungan antara diameter dan tinggi pohon dengan besarnya biomassa.

Penelitian ini bertujuan untuk mengetahui besarnya biomassa komponen pohon seperti batang, cabang dan ranting jenis ekaliptus (E. urophylla) dan penyusunan model penduga biomassa di atas permukaan tanah jenis ekaliptus (E. urophylla) pada HTI PT. Toba Pulp Lestari.

\section{METODE PENELITIAN}

Model pendugaan biomassa merupakan suatu model yang menggunakan dan mencari keterkaitan antara satu atau beberapa peubah bebas untuk menduga peubah tidak bebasnya. Dimensi yang dipakai untuk menduga biomassa meliputi diameter setinggi dada, tinggi pohon. Sebab diameter pohon dan tinggi pohon merupakan parameter terbaik untuk menduga biomassa pohon dan hemat dari segi waktu dan biaya (Brown, 1997).

Dalam penelitian ini besarnya biomassa yang akan diukur hanya mencakup biomassa di atas tanah (biomassa batang, cabang dan ranting). Sehingga peubahpeubah tak bebas yang digunakan pada penelitian ini meliputi (i) biomassa batang (B. batang) : total berat kering batang utama; (ii) biomassa cabang (B. cabang) : total berat kering kese-luruhan bagian cabang; dan (iii) biomassa ranting (B. ranting) : total berat kering keseluruhan bagian ranting.

Sedangkan peubah-peubah bebas yang digunakan pada penelitian ini meliputi (i) diameter setinggi dada (dbh); diameter batang yang diukur pada ketinggian 1,3 m dari permukaan tanah; (ii) tinggi pohon total (h) : tinggi pohon dari pangkal pohon sampai batas batang yang dapat dipergunakan; dan (iii) panjang batang seksi (p) : jarak suatu titik dengan titik lainnya yang mengikuti keadaan batang.

Data yang dikumpulkan atas pengukuran diameter, tinggi, panjang batang dan berat per seksi dari 21 pohon contoh dari 7 kelas 
umur yang ditebang. Pemilihan pohon sampel dilakukan secara purposive sampling.

Untuk perhitungan kadar air kayu, diambil sampel dari bagian batang sebagai contoh uji dengan ukuran $5 \times 5 \times 5 \mathrm{~cm}^{3}$ dengan 3 ulangan. Tiap contoh uji dikeringkan me nggunakan oven pada suhu $\pm 105{ }^{\circ} \mathrm{C}$, kemudian diukur volume dan beratnya pada saat kering tanur.

Untuk melakukan perhitungan volume, dilakukan pada masing-masing seksi dengan menggunakan rumus:

$$
\begin{gathered}
V=\frac{1}{8} \pi\left(\frac{d p+d u}{100}\right)^{2} x L_{(\text {Simon, 1987) }} \\
\text { dimana }: \\
\text { dp }=\text { diameter pangkal }(\mathrm{cm}) \\
\mathrm{du}=\text { diameter ujung }(\mathrm{cm}) \\
\mathrm{L}=\text { panjang seksi }(\mathrm{m}) \\
\mathrm{Vi}
\end{gathered}
$$

Sedangkan perhitungan kerapatan kayu dihitung secara langsung dengan membagi berat dan volume dalam satuan metric, dengan rumus sebagai berikut:

$$
R=\frac{\text { Massa }}{\text { Volume }}\left(\mathrm{gr} / \mathrm{cm}^{3}\right)(\text { Haygreen \& Bowye, 1996) }
$$

Untuk perhitungan biomassa dengan pendekatan volume diperoleh dengan mengalikan volume setiap bagian pohon dengan nilai kerapatan kayu tersebut dengsn rumus :

$$
\mathbf{B}=\mathbf{V} \times \mathbf{R}
$$

$$
\begin{aligned}
\text { dimana } & \text { : } \\
\mathrm{B} & =\text { biomassa } \\
\mathrm{V} & =\text { volume } \\
\mathrm{R} & =\text { nilai kerapatan kayu }
\end{aligned}
$$

Perhitungan biomassa dilakukan dengan penimbangan langsung. Berat kering total masing-masing bagian pohon diperoleh dengan menimbang langsung dengan rumusan Haygreen dan Bowyer (1996).

$$
\begin{aligned}
& B K=\frac{B B}{1+\left(\frac{\% K A}{100}\right)} \\
& \% K A=\frac{B B c-B K c}{B K c} X 100 \% \\
& \text { dimana: } \\
& \text { BK } \quad=\text { Berat Kering } \\
& \text { BB } \quad=\text { Berat Basah } \\
& \text { BBc } \quad=\text { Berat basah Contoh } \\
& \text { BKc } \quad=\text { Berat Kering Contoh } \\
& \% \text { KA } \quad=\text { Persen Kadar Air }
\end{aligned}
$$

Penyusunan model allometrik pendugaan biomassa bagian pohon dilaksanakan dengan menghubungkan antara biomassa dengan dimensi pohon (diameter dan tinggi) yang disusun dalam bentuk persamaan regresi sebagai berikut :

$$
\begin{aligned}
\mathrm{B}= & \mathrm{a}-\mathrm{bD}+\mathrm{cD}^{2}+\mathrm{dD}^{3} \text { (Hairiah et al, 1999) } \\
\mathrm{B}= & \mathrm{a}-\mathrm{bD}+\mathrm{cD}^{2} \cdot(\text { Brown et al, 1989) } \\
\mathrm{B}= & \mathrm{a} \mathrm{D}^{\mathrm{b}} \text { (Brown et al, 1989) } \\
\mathrm{B}= & \mathrm{a}\left(\mathrm{D}^{2} \mathrm{H}\right)^{\mathrm{b}} \text { (Ogawa et al, 1965) } \\
\mathrm{B}= & \mathrm{a}+\mathrm{bD}^{2} \mathrm{H} \text { (Brown et al, 1989) } \\
& \text { dimana : } \\
& \mathrm{B}=\text { Biomassa }(\mathrm{kg})
\end{aligned}
$$


$\mathrm{D}=$ Diameter setinggi dada $(\mathrm{dbh}, \mathrm{cm})$

$\mathrm{a}, \mathrm{b}, \mathrm{c}=$ Koefisien elevasi

$\mathrm{H}=\operatorname{tinggi}(\mathrm{m})$.

Pemilihan model allometrik terbaik untuk pendugaan biomassa pohon terhadap model-model yang disusun dilakukan pemilihan model yang terbaik yang akan digunakan dengan kriteria koefisien determinasi $\left(\mathrm{R}^{2}\right)$, Mean Square Error (MSE) dan nilai Jumlah Kuadrat Sisa Dugaan / Predicted Residual Sum of Square (PRESS) oleh Drapper et, al (1996).

\section{HASIL DAN PEMBAHASAN}

\section{a. Sebaran Rata-rata Bio- massa Bagian Pohon}

Pendugaan biomassa ekaliptus (E.urophylla) baik batang, cabang dan ranting) didasarkan pada dimensi diameter setinggi dada dan tinggi yang mempunyai hubungan erat dengan biomassa.

Hasil penelitian dengan daur teknis 7 tahun terlihat bahwa adanya peningkatan biomassa batang, cabang dan ranting seiring dengan meningkatnya umur tanaman. Pada kelas umur 1 tahun biomassa batang sebesar 3,10 kg dan biomassa batang ini akan meningkat hingga pada umur 7 tahun sebesar 219,78 kg dengan rata-rata pertumbuhan biomassa batang 106,72 kg/tahun. Pada kelas umur 1 tahun biomassa cabang adalah sebesar 1,56 kg dan biomassa cabang ini akan meningkat hingga pada kelas umur 4 tahun sebesar 6,97 kg dengan rata-rata pertumbuhan biomassa cabang 5,10 kg. Pada kelas umur 1 tahun biomassa ranting sebesar $1,54 \mathrm{~kg}$ dan biomassa ini meningkat hingga pada kelas umur 4 tahun sebesar 4,97 kg dengan ratarata pertumbuhan biomassa ranting 3,19 kg.

Besarnya biomassa dari bagian-bagian pohon (batang, cabang dan ranting). Persentase rata-rata setiap bagian pohon tertinggi sampai terendah berturut-turut seperti berikut, biomassa batang (93\%), biomassa cabang (4\%) dan biomassa ranting (3\%).

\section{b. Kadar Air dan Kerapatan}

Untuk model pendugaan biomassa sifat fisikometrik kayu yang ditonjolkan adalah kadar air kayu. Pengukuran kadar air kayu sangat berguna untuk mengetahui kandungan air yang ada dalam kayu, mengingat bahwa bahwa kayu terdiri dari air dan materimateri penyusunnya. Di dalam pendugaan biomassa ekaliptus pengukuran kadar air sangat penting dimana kadar air ini digunakan untuk mengkonversi berat basah batang, cabang, dan ranting ke dalam berat kering. Pengukuran kadar air ini dilakukan sampai kondisi kering tanur. 
Dari pengukuran kadar air dapat diterangkan bahwa persen kadar air meningkat dengan kenaikan kelas umur. Persentase rata-rata kadar air terendah terdapat pada kelas umur 1 tahun dengan persentase 50,916 \% dan rata-rata kadar air tertinggi terdapat kelas umur 7 tahun dengan persentase 127,767 \%.

Kadar air erat sekali hubungannya dengan kerapatan. Dari hasil penelitian ini terlihat bahwa nilai kerapatan akan meningkat dengan semakin naiknya kelas umur. Kerapatan terendah pada umur 1 tahun $\left(0,4829 \mathrm{gr} / \mathrm{cm}^{3}\right)$ dan kerapatan tertinggi terdapat pada umur 7 tahun $\left(0,5838 \mathrm{gr} / \mathrm{cm}^{3}\right)$ dengan rata-rata nilai kerapatan 0,5079 $\mathrm{gr} / \mathrm{cm}^{3}$.

\section{c. Penyusunan dan Pemilihan Model Pendugaan Bio- massa Pohon}

Salah satu cara yang efektif untuk menduga biomassa adalah dengan menyusun metode allometrik dengan cara memanfaatkan data hasil inventarisasi lapangan terhadap dimensidimensi pohon (diameter setinggi dada dan tinggi) yang diduga memiliki tingkat keeratan yang kuat dengan besarnya biomassa. Brown (1997) membuat hipotesis bahwa biomassa dapat diduga oleh dimensi pohon (diameter setinggi dada dan tinggi total) maka model pendugaan biomassa dapat disusun sebab diameter setinggi dada dan tinggi merupakan data inventarisasi yang terbaik untuk menduga biomassa.

$$
\text { Model pendugaan yang }
$$
digunakan untuk menduga biomassa di atas permukaan tanah terdiri dari model-model hasil penelitian yang sudah umum digunakan dengan peubah bebas dimensi-dimensi pohon (diameter setinggi dada dan tinggi total) disusun dalam bentuk persamaan regresi.

Pemilihan model pendugaan biomassa terbaik dilakukan dengan berdasarkan nilai koefisien determinasi (R), kuadrat tengah sisa dan nilai PRESS (Draper and Smith, 1992). Selain itu model yang baik harus memenuhi suatu asumsi kenormalan dan kehomogenan ragam sisaan. Modelmodel terbaik pendugaan biomassa pohon ekaliptus (E. urophylla) dan bagiannya terlihat pada table berikut ini. 


\begin{tabular}{|c|c|c|c|c|c|c|}
\hline Biomassa & Persamaan & $\mathbf{R}^{2}$ & $S$ & FHit & MSE & PRESS \\
\hline Batang & $\begin{array}{l}B=0.0493 \\
\left(D^{2} H\right)^{0,883}\end{array}$ & 98,3 & 0,20 & 1083,41 & 0,04 & 1,100 \\
\hline Cabang & $\begin{array}{l}\mathrm{B}=0,83- \\
0,089 \quad \mathrm{D}+ \\
0,0557 \mathrm{D}^{2}- \\
0,00188 \mathrm{D}^{3}\end{array}$ & 90,6 & 0,53 & 54,94 & 0,286 & 6,813 \\
\hline Ranting & $\begin{array}{lcc}\mathrm{B}= & 5,01 & - \\
1,17 \quad \mathrm{D} & + \\
0,113 & \mathrm{D}^{2} & - \\
0,00284 \mathrm{D}^{3} & \end{array}$ & 72,8 & 0,64 & 15,14 & 0,412 & 9,494 \\
\hline Total & $\begin{array}{l}B=0,396 \\
\left(D^{2} H\right)^{0,735}\end{array}$ & 97,3 & 0,21 & 692,30 & 0,044 & 1,195 \\
\hline
\end{tabular}

Keterangan : $\mathrm{B}=$ Biomassa; $\mathrm{D}=$ Diameter $; \mathrm{H}=$ Tinggi

Dari semua model-model terpilih di atas sebagian besar cukup stabil dan dapat diandalkan dalam menduga biomasaanya karena memiliki nilai $\mathrm{R}^{2}$ antara $72,8 \%-98,3 \%$.

\section{d. Potensi Biomassa di Atas Permukaan Tanah}

Biomassa tegakan hutan dipengaruhi oleh umur tegakan hutan dan kualitas tempat tumbuh. Tegakan ekaliptus akan cepat tumbuh dengan riap yang tinggi bila tumbuh pada tapak yang berkualitas. Hal ini berarti bahwa tanaman akan mampu mengikat bahan organik (biomassa) dalam jumlah besar.

Dugaan besarnya potensi biomassa di atas permukaan tanah jenis ekaliptus (E. urophylla) per pohon dan per ha menurut kualitas tapak dan kelas umur pada tegakan ekaliptus PT. TPL dapat dilihat pada table berikut ini :

\begin{tabular}{|c|r|r|r|r|r|r|r|r|}
\hline \multirow{2}{*}{$\begin{array}{c}\text { KU } \\
\text { (thn) }\end{array}$} & \multicolumn{2}{|c|}{ SI 21,36} & \multicolumn{2}{c|}{ SI 22,80} & \multicolumn{2}{|c|}{ SI 24,24} & \multicolumn{2}{|c|}{ SI 25,68 } \\
\hline & $\mathrm{Kg} / \mathrm{phn}$ & $\mathrm{Kg} / \mathrm{ha}$ & $\mathrm{Kg} / \mathrm{phn}$ & $\mathrm{Kg} / \mathrm{ha}$ & $\mathrm{Kg} / \mathrm{phn}$ & $\mathrm{Kg} / \mathrm{ha}$ & $\mathrm{Kg} / \mathrm{phn}$ & $\mathrm{Kg} / \mathrm{ha}$ \\
\hline 1 & 4,21 & 4.674 & 4,41 & 4.898 & 4,61 & 5.122 & 4,81 & 5.347 \\
\hline 2 & 22,38 & 24.863 & 23,66 & 26.284 & 24,94 & 27.707 & 26,22 & 29.133 \\
\hline 3 & 58,79 & 65.311 & 63,81 & 70.897 & 68,85 & 76.497 & 73,91 & 82.108 \\
\hline 4 & 111,97 & 124.400 & 121,23 & 134.684 & 130,51 & 144.992 & 139,80 & 155.321 \\
\hline 5 & 149,69 & 166.306 & 161,15 & 179.043 & 172,64 & 191.806 & 184,15 & 204.595 \\
\hline 6 & 173,53 & 192.790 & 183,65 & 204.039 & 193,80 & 215.307 & 203,95 & 226.593 \\
\hline 7 & 182,98 & 203.291 & 195,68 & 217.397 & 208,40 & 231.531 & 221,14 & 245.690 \\
\hline
\end{tabular}


Indonesia sangat berpotensi sebagai negara penyerap karbon terbesar ketiga di dunia sebab negara kita memiliki luas hutan tropis ketiga terluas di dunia setelah Brazil dan Zaire. Potensi pasar karbon dengan asumsi adanya partisipasi negara-negara Eropa dan Amerika Serikat diprediksi sebesar 53 Megaton $\mathrm{CO}^{2}$ dengan harga karbon US\$ 0,76 /ton $\mathrm{CO}^{2}$ dengan total pendapatan berkisar antara US\$ 18 juta - US\$ 39 juta. Dari situasi ini total volume CDM Indonesia adalah sebesar 36 juta ton $\mathrm{CO}_{2}$ /tahun atau setara dengan pangsa pasar $6 \%$ dari potensi pasar karbon internasional.

\section{KESIMPULAN}

\section{a. Kesimpulan}

Dari hasil dan pembahasan penelitian ini dapat diambil kesimpulan sebagai berikut:

1. Batang merupakan bagian pohon yang memiliki persentase biomassa di atas permukaan tanah terbesar dibandingkan dengan cabang dan ranting. Berikut adalah persentase rata-rata biomassa bagian-bagian pohon ekaliptus (E.urophylla) : biomassa batang (93\%), biomassa cabang (4\%) dan biomassa ranting (3\%).

2. Model-model allometrik terbaik yang disusun dalam menduga biomassa pohon dan bagian-bagiannya adalah sebagai berikut :

a. Biomassa batang; $\mathrm{B}=$ $0,0943\left(D^{2} H\right)^{0,883}$ dengan $\left(R^{2}=98,3 \%\right)$

b. Biomassa cabang; $\mathrm{B}=0,83$

- 0,089 D + 0,5557D ${ }^{2}-$ $0,00188 \mathrm{D}^{3}$ dengan $\left(\mathrm{R}^{2}=\right.$ 90,6\%).

c. Biamassa ranting; $B=5,01$

$-1,17 \mathrm{D}+0,113 \mathrm{D}^{2}-$ $0,00284 \mathrm{D}^{3}$ dengan $\left(\mathrm{R}^{2}=\right.$ $72,8 \%)$.

d. Biomassa total; $\mathrm{B}=0,396$ $\left.\left(D^{2} H\right)^{0,735}\right)$ dengan $\left(R^{2}=\right.$ 97,3\%).

3. Dimensi pohon (tinggi dan diameter) merupakan parameter terbaik untuk biomassa bagian-bagian pohon. Model pendugaan batang dan biomassa total tersusun dengan dua peubah (tinggi dan diameter) sedangkan model pendugaan biomassa cabang dan ranting hanya menggunakan satu peubah saja (diameter).

\section{b. Saran}

Pendugaan biomassa pohon perlu memperhatikan faktorfaktor luar yang dapat mempengaruhi besarnya biomassa seperti perlakuan silvikultur, kelembaban, ketinggian tempat dan kualitas tempat tumbuh.

Perlu dilakukan penelitian pendugaan biomassa di bawah 
permukaan tanah untuk mengetahui dugaan biomassa total sehingga diketahui proporsi Biomass Expansion Factor (BEF) di atas permukaan tanah dan di bawah permukaan tanah jenis ekaliptus (E. urophylla).

\section{PUSTAKA}

Anonimus, 2000. Buletin Kehutanan dan Perkebunan. Badan Penelitian dan Pengembangan Kehutanan, Bogor. Vol.1 No.1, 2000.

Adisasmitho, W. Handoko, Sugandi, dan Gunardi (1998). Mitigation assessment of climate change in Indonesia. The State Ministry of Invirontment. Jakarta.

Boscolo, M. and J. Buongiorno, 1997. Managing Tropical rain forest for timber, carbon storage and tree diversity. Commonwealth forestry Review, 76 (4); 246-253.

Brown. S, 1997. Estimating Biomass change of tropical forest a primer FAO, Forestry paper No. 134. USA.

Chapman SB, 1976. Production ecology and nutrient Budgets, in Chapman, SB. (eds) Methods in Plant ecology. Second edition.
157-228. Blackwell Scientific Publisher, Oxford.

Draper NR, H. Smith, 1992. Analisis Regresi Terapan. Gramedia. Jakarta.

Haygreen JG, JL Bowyer, 1996. Hasil hutan dan Ilmu kayu (suatu pengantar), edisi 4. UGM Press.

Hendra. S, 2002. Model Pendugaan Biomassa pohon Pinus mercusii Jung et de Vriese di KPS Cianjur PT. Perhutani III Jawa Barat.

Khaerudin. 1999. Pembibitan tanaman HTI. PT. Penebar Swadaya. Cetakan 2. Jakarta.

Kharmacharya SB, KP Singh, 1992. Biomass and Net Production of teakin A dry Tropical Region in India. Forest Ecology and Management 55 (1992) p: 233247/ Elsevier science Publishers B.V. Amsterdam.

Kusmana, C.S. Sabiham, K Abe dan H Watanabe. 1992. An Estimation of above ground Biomass of a Mangrove Forest in East Sumatra, Indonesia. Tropics 1(4): 143-257. Syst. 5:59.

Lugo. AE, SC Snedaker, 1974. The Ecology of Mangrove. Ann Rev Ecol. 64. 
Mulyono S. 1991. Operation research. Lembaga Penerbit Fakultas Ekonomi UI, Jakarta. Hal: 1-5.

Ogawa H, Kyoji Yuda, K, Ogino, T Kira. 1965. Comparative Ecological studies on tree Main types of forest vegetation ion Thailand II. Plant Biomass. Nature \& Life in SE. Asia 4; 50-80.

Samani, M. 1997. Pengaruh serangan jamur Upas (Corticum salmon color.
Berk \& Br.). Skripsi Fakultas Kehutanan Universitas Mulawarman.

Satoo T, HAI Madgwick. 1982. Forest to offset the green house effect. Journal of forestry: Juli 1959.

Simon H. 1987, Manual Inventory Hutan: UI Press.

Whitmore TC. 1985. Tropical Rain Forest of The Far East. Oxford University Press, New York. 